\title{
THE IMPLEMENTATION OF MODERN GEOCENTRIC DATUM: A REVIEW
}

\author{
N. M. Yazid ${ }^{1}$, A.H.M.Din ${ }^{1,2} *$, N.M. Abdullah ${ }^{3}$ and A. H. Omar ${ }^{1}$ \\ ${ }^{1}$ Geomatics Innovation Research Group (GnG), ${ }^{2}$ Geoscience and Digital Earth Centre (INSTEG), Faculty of Built Environment and \\ Surveying, Universiti Teknologi Malaysia, 81310 Johor Bahru, Johor, Malaysia, \\ ${ }^{3}$ Fakulti Kejuruteraan Awam dan Alam Sekitar, Universiti Tun Hussein Onn Malaysia, 86400, Parit Raja, Johor. \\ amihassan@utm.my
}

KEY WORDS: Geocentric Datum, Modern Datum, ITRF, Parameters, Reference Frame, Epoch

\begin{abstract}
:
A dynamic datum denotes a coordinate datum in real-time linked with the International Terrestrial Reference Frame (ITRF) in order to provide a dynamic ITRF-like datum to the users. The ITRF is dynamic and updating every few years as its stations' coordinates consider the motion of earth's tectonic plate and other deformations. This paper is an effort to review the implementation of dynamic geocentric datum techniques from a few countries. An overview of dynamic geocentric datum implements Malaysia, Australia, New Zealand, Uzbekistan, Israel and Brunei will be summarized to support the future application. Thus, a review consists of a type of datum; datum parameters, reference frame and epoch will be discussed and outlined. This initiative is the significance for the advancement of the future datum development.
\end{abstract}

\section{INTRODUCTION}

The National Geodetic Survey (NGS, 1986) describes the geodetic datum as "a set of constant specifying the coordinate system used for geodetic control in order to estimate the point coordinates on the Earth". Classically, a geodetic datum is a reference surface, generally an ellipsoid of revolution of adopted size and shape, with origin, orientation and scale defined by a geocentric terrestrial frame (Mostafa Rabah et al., 2016). Besides, geodetic datum represents the size and shape of the ellipsoid and a set of parameters that illustrates a coordinate system, comprising an origin, orientation and scale with regards to the 3D Cartesian System which applicable for geodetic implementations (Drewes, 2009. and Jekeli, 2012).

On the other hand, the geocentric datum illustrates a best-fit ellipsoid where its origin and orientation with regards to the Earth-centred Earth-fixed (ECEF) coordinate system. The adoption of geocentric datum is categorized into three hierarchical level; global, regional and national. The global adoption of a geocentric datum is a main datum followed by the regional and national geocentric datum whereby the adoption of geocentric datum is particularly consistent with the International Terrestrial Reference System (ITRS). The ITRS is accomplished through the International Terrestrial Reference System (ITRF) which demonstrates the paramount accessible global geocentric datum (Shariff et al., 2017).

The foremost significance of geocentric datum is that a single homogeneous geodetic datum can be recognized throughout the world. Thus, geocentric datum at national level can be comprehended by linking its national reference frame to the subset of geodetic stations from International GNSS Service (IGS) of the global frame from ITRF, hence implementing geocentric datum. The definite aims of modern geodesy is to present a highly stable geocentric reference datum for scientific purpose, such as precise orbit determination, monitoring sea level rise, measuring plate tectonics and so on (Angermann et al., 2003).

Every country tremendously requires geocentric datum with an appropriate procedure correlate with its regular update and maintenance. There are several alternatives towards the advancements of national geocentric datum such as updating a static datum regularly and implementation of the semi-dynamic and dynamic geocentric datums. A static datum is described as the datum that remains unchanged whereby the coordinates of geodetic stations are held fixed. While, a semi-dynamic datum (semi-kinematic datum) is described as the change of coordinates and it is implemented for calculating coordinates at different moments in times. On the other hand, dynamic datum (kinematic datum) is defined as a set of physical points attached to Earth's surface. The points are fixed velocities and coordinates that continuously change over time due to crustal movements (Ronen and Even-tzur, 2017).

On the other hand, geodetic datum also involves datum transformation through a determination of a mathematical relationship to be applied in transforming a set of coordinates from one geodetic datum to another. Thus, .two significance parts need to be considered in coordinate transformation from one datum to another. Firstly, the location of the geometric centers of each reference ellipsoid with regard to the center of earth's gravity or with regard to each other. Secondly, the differences of size and shape between the two ellipsoid (Dawod and Resrach, 2014)

With the advent of satellite positioning techniques and growth of utilizing these space systems all over the world hence, the geodetic datum transformation become a major practice in transforming the coordinates from the global geodetic datum to several local datum for different countries (Moore and Smith: 1998 ; Reit, 1998).

\footnotetext{
* Corresponding author
} 
Thus, this paper is to review the techniques applied towards development of geocentric datum and datum transformation for a region. Six countries are selected in study in order to review the geocentric datum techniques implements in each country; Malaysia, Australia, New Zealand, Uzbekistan, Israel and Brunei.

\section{GEOCENTRIC DATUM IMPLEMENTATION FOR MALAYSIA, INDONESIA, AUSTRALIA, NEW ZEALAND, UZBEKISTAN, ISRAEL AND BRUNEI}

\subsection{Overview of Geocentric Datum in Malaysia}

The Geocentric Datum of Malaysia (GDM 2000) was realized by the Department of Survey and Mapping Malaysia (DSM2000) to demonstrate a global and homogeneous coordinate system across the country. The adoption of GDM 2000 is based on ITRF 2000 at epoch 1st January 2000. GDM2000 was realized through a permanent network of active GPS stations known as Malaysia Active GPS System (MASS) stations (Zulkifli et al., 2019). Nevertheless, the GDM 2000 maintain as a static datum where all site coordinates are remain unchanged with time.

Nowadays, accessing accurate real time satellite ephemeris and clock data has begun to receive increased attention among the scientific users of Global Navigation Satellite System (GNSS)

(Ramachandran et al., 2019).The measurements determined via GNSS surveying, specifically in Malaysia, are currently not subject to any sort of validation, primarily involving the Network Real-Time Kinematic (N-RTK) technique (Gill et al., 2016).DSMM ascertain a new Continuously Operating Reference Station (CORS) network known as the Malaysian Real-Time Kinenatic GNSS Network (MyRTKnet) with 78 reference stations nationwide in order to enhance the MASS stations and assist the generation of network-based positioning solutions in year 2002. Nevertheless, these stations experienced land displacement on 26 December 2004 in the range of 1.5-1.7 $\mathrm{cm}$ and orientation mostly in the south-west direction due to the co-seismic motion from the Aceh earthquake (DSMM,2009 and Shariff et al., 2014.).

The output from Nias and Bengkulu earthquakes showed land displacements in the range of $1-6.5 \mathrm{~cm}$ and $1-3 \mathrm{~cm}$, correspondingly in the south-west direction. Thus, a revision of the GDM 2000 is accomplished based on epoch 2006 and 2009. GDM2000 needs to be updated in order for the issues to be rectified. However, due to tectonic motion, the geodetic datum would need to be updated over time. This then would result in an array of epochs for the geodetic datum causing confusion at the user level.(Gill et al., 2016)

Datum transformation is required in this process using Bursawolf Transformation. The transformation involves three geocentric datum shift parameters $(\Delta \mathrm{X}, \Delta \mathrm{Y}, \Delta \mathrm{Z})$, three rotation elements (RX, RY, RZ) and a scale factor $(1+\Delta \mathrm{L})$ based on Geodetic Reference System 1980 (GRS80) reference ellipsoid.

\subsection{Overview of Geocentric Datum in Australia}

The latest national datum of Australia is Geocentric Datum of Australia (GDA 2020) based on GRS80 reference ellipsoid (ICSM, 2018). GDA 2020 coordinates were computed using a rigorous, 3D network adjustment of all available GNSS and terrestrial data from Commonwealth, state and territory jurisdictional archives. This datum adjustment is conducted by Geoscience Australia with input from geodetic specialist representatives from all jurisdictional survey organisations.GDA 2020 is a static datum just like the old datum of Australia, GDA 94. A static datum represents the coordinates of features like roads, buildings and property boundaries remain unchanged with time even if the plate tectonic motion happened.

The datum transformation from GDA 2020 is to certify spatial data can be more closely associated to positions observed applying Global Navigation Satellite System (GPS) (ICSM, 2019). Thus, ITRF 2014 coordinates and velocities of the 109 Australian Fiducial Network (AFN) are mapped ahead to the epoch of January 1, 2020 using plate motion model, conventional Euler plate model. Whereby, 3-parameter model can be expressed as a 7-parameter transformation with only rates of change rotation components. From January 12017 until January 1 2020, the difference between ITRF 2014 coordinates (at the observed epoch) and GDA2020 coordinates will constantly converge as the Australia tectonic plate changes $7 \mathrm{~cm}$ per year in a north-easterly direction. Thus, there will be a rising conjunction in the coordinates of the GDA2020 and ITRF2014.Thus, GDA 2020 grants a more robust and accurate datum which is thoroughly associated to global positioning systems like Global Navigation Satellite System (GNSS) (GA, 2019).

\subsection{Overview of Geocentric Datum in New Zealand}

New Zealand stays across the obliquely convergent Australian and Pacific plate boundary. To the northeast of New Zealand the Pacific plate is subducted underneath the Pacific plate. Through central New Zealand the oblique collision of the continental plates has resulted in a combination of strike slip and uplift motion with horizontal motions of 40-55 mm/yr along the plate boundary (Walcott, 1984). Besides, New Zealand also undergo the effects of other deformation occurents such as major earthquakes, volcanic activity and so on. After the establishment of the first national geodetic datum in New Zealand known as New Zealand Geodetic Datum 1949 (NZGD49), the consequences of crustal deformation effected in a regular degradation in the datum's accuracy up to $2.5 \mathrm{~cm}$ since its definition (LINZ, 2019). Thus, it resulted the lowest accuracy achievable and distortions of up to $5 \mathrm{~m}$ (Bevin and Hall, 1995).

Hence, New Zealand realized a new geocentric datum in year 2008 known as New Zealand Geodetic Datum 2000 (NZGD2000) with a reference epoch of 1 January 2000 (2000.0) to account errors in NZGD49 as well as datum deficiency over time due to deformation (Blick et al., 2010). There are a few difference between NZGD1949 and NZGD2000, whereby NZGD1949 is a local horizontal datum and static datum. While, NZGD2000 is a geocentric three dimensional datum. It is also a semi-dynamic datum integrating a deformation model with coordinates and GRS80 as a reference ellipsoid. Datum is transformed using grid transformation, and the 3 and 7 parameter similarity transformations.

\subsection{Overview of Geocentric Datum in Uzbekistan}

The physical environment of Uzbekistan is varied, ranging from the flat, desert topography that consists almost 80 percent of the country's territory to mountain peaks in the east reaching about 
$4500 \mathrm{~m}$ above sea level. Uzbekistan is referred to Coordinate System of 1942 (CS-42) based on Krasovsky reference ellipsoid with Pulkovo's origin and realized static datum transformation. CS-42 is a high quality and accuracy for the standards of the day. Nevertheless, this accuracy is inadequate to handle with modern necessities and technologies.

Uzbekistan is a dynamic region, lying across the Eurasia tectonic plate boundary. Thus, there are ground movements across the country at approximately $3 \mathrm{~cm} / \mathrm{yr}$ in north-east direction, omitting the effects of large eathquakes. It is about $2.1 \mathrm{~m}$ in the 70 years since the currents CS42 Geodetic is developed.

In order to enhance the Uzbekistan geodetic reference frame, the new State Geodetic Network (SGN) is established, primarily using GPS measurements with 50 points of Continuously Operating Reference Stations (CORS). The datum transformation in Uzbekistan using Molodensky transformation that requires only the 3 parameters from WGS84 coordinates to CS-42 system (Fazilova, 2017)

\subsection{Overview of Geocentric Datum in Israel}

The latest geodetic datum for Israel is Israel Geodetic Datum 2005 (IGD05/12) updated in 2012 based on 17 stations located on the Sinai sub plate. IGD05/12 is updated after seven years establishment of IGD05 using 7- parameters Bursa-wolf transformation. Israel is located in three major tectonic plates, the African, Arabian and Eurasian.

The major region of Israel on the Sinai subplate whereby a part of the African plate which another part on Arabican plate (Wdowinski et al., 2004). The border between the Sinai subplate and the Arabian plate is known as the Dead Sea Transform (DST), which is a series of faults from the tip of the Red Sea to the Taurus mountains in Turkey (Garfunkel, 1981; Garfunkel and Ben-Avraham, 1996). These faults are the major earthquakes in the region that happen every 100 years or so .Israel is defined as the semi-dynamic datum and it is designed as a series of static datums that are connected to the ITRS I in one of is realizations and at a specific epoch (Ronen and Eventzur, 2017).

\subsection{Overview of Geocentric Datum in Brunei}

Survey Department Brunei Darussalam is accountable for the establishment and maintenance of horizontal and vertical control points for geodetic applications. The adoption of the Geocentric Datum for Brunei Darussalam (GDBD) is referred on a network of permanent GPS tracking stations in Brunei and fits inti the global ITRF global framework. The IERS maintains the terrestrial reference system through an ITRF, which is determined by realizing the geocentric Cartesian coordinates and velocities of global tracking stations derived from the analysis of VLBI, SLR and GPS data.

Thus, the authors could assume Brunei realizing a semidynamic datum due to the elements of estimating a horizontal velocities field. This estimation is significance towards semidynamic datum establishment to maintain the coordinate accuracy of sites (Ching and Chen, 2016).

The latest adoption of ITRF series is the ITRF2005, released in 2008 based on $1^{\text {st }}$ January 2000 reference epoch. GDBD also adopts 7-Parameter Bursa-Wolf transformation model for transforming three-dimensional Cartesian co-ordinates between two datums from old datum, Borneo Triangulation 1949 (BT48) to new datum, GDBD2009.

\section{RESULTS AND DISCUSSIONS}

As discussed in the previous section, every country comprised of a local datum. Each local datum is established based on different parameters as shown in Table 1. Where, the geocentric datum of Malaysia, Australia, Uzbekistan, Israel and Brunei are established based on a static datum. The coordinates of the geodetic stations are remained to that reference epoch (Grant and Pearse, 1995). Thus, it only accurately reflects the actual position, connecting to the ITRF on a specific reference epoch (Shariff et al., 2017).

However as mentioned in Section 1.0, semi-dynamic datum is described as the change of coordinates and it is implemented for calculating coordinates at different moments in times. In this study, New Zealand and Brunei implement semi-dynamic datum. There is no standard method to implement a semidynamic datum as it completely depends on the seismic activity of a region.

A study is conducted by Shariff et al., (2017) towards the implementation of semi-dynamic datum in Malaysia. It is based on single reference epoch whereby coordinates of the observation epoch are propagated to the reference epoch and able to propagate to any epoch with inclusion of deformation model. The deformation model is then updated when an earthquake happens (Winefield et al., 2010).

Thus due to the dynamical of the Earth, semi-dynamic or dynamic datum is suitable towards the implementation of datum in a region. Based on a geodetic prospect, a semi-dynamic datum is adequately easy to apply and manage. The datum plays static and the deformation model can be neglected for low accuracy users (meter level). The deformation model is required to maintain the accuracy of the geodetic system and assist with the effects of crustal deformation. For the unstable country like New Zealand, Uzbekistan and Israel, the adoption of semidynamic datum seems reliable due to plate tectonics amounting to movements of the magnitude/year. If static datum is adopted, the relative accuracy tolerance would have been exceeded after only one year(Blick and Grant, 2015).

Besides, the implementation of semi-dynamic datum does not need a costly and time-consuming geodetic datum update whenever an earthquake occurs. However, the implementation of semi-dynamic datum needs the revision of cadastral database as well. Practically, this is difficult to be implemented in a region that has internal problems regarding to cadastral database like Malaysia (Shariff et al., 2017).

In the datum transformation perspective, each country is implementing 7-parameter Bursa-wolf transformation except Uzbekistan (3 parameters Molodensky transformation model). However, there are implementation of 14 parameters like United State which not included in this study. There are some limitations towards implementations of 14-parameter transformation.

Firstly, the needs of the position time series of the common points in the ITRF frame and the coordinates in the target frame which organize the projection geodetic datum. Practically, the 
points of control points located on the crust that moving within the frame will be neglected hence will be absorbed by 14parameter. However in the long terms, the transformation accuracy will be effected(Ronen and Even-tzur, 2017).The velocity of the tectonic plate at the measured location is needed and can be applied into an equation given in Soler and Marshall (2002).

14-parameter transformation approach is suggested for the extremely suitable country like Australia, Malaysia and Brunei with a few relative deformation across its landmass (Donnelly et al., 2014). Therefore, the 14-parameter transformation is able to accurately incorporate the national-scale plate motion. This will give advantage to the users because the utilization of deformation is unnecessary. However, a country should be at least has a capacity to handle 7-parameter transformations.
This approach would not perform in a country with a significance relative deformation like New Zealand, Uzbekistan and Israel. There is major relative deformation that would not be modelled effectively using a simple 14-parameter transformation for coordinate transformation and propagation even at a national scale. Therefore, the processes of coordinate transformation and propagation need to be separate, respectively.

On the other hand, Molodensky transformation model will present satisfactory result for a small region. Where the effect of the unknown rotation or scale factor will become significant and lead to distortion with increasing of research area. Besides, Molodensky transformation model provides adequate results for topographic purpose.

\begin{tabular}{|c|c|c|c|}
\hline Country & Datum & $\begin{array}{c}\text { Reference Frame and } \\
\text { Epoch }\end{array}$ & Parameters \\
\hline Malaysia & $\begin{array}{c}\text { Geocentric Datum of Malaysia } \\
\text { (GDM 2000) } \\
\text {-Static Datum }\end{array}$ & ITRF2000 at epoch 2000.0 & $\begin{array}{l}7 \text {-parameters Bursa-Wolf } \\
\text { Transformation model }\end{array}$ \\
\hline Australia & $\begin{array}{c}\text { Geocentric Datum of Australia } \\
\text { (GDA 2020) } \\
\text {-Static Datum }\end{array}$ & ITRF 2014 at epoch 2020.0 & $\begin{array}{l}\text { 7-parameter and similarity } \\
\text { transformation (Bursa-wolf) }\end{array}$ \\
\hline New Zealand & $\begin{array}{c}\text { New Zealand Geodetic Datum } \\
2000 \text { (NZGD2000) } \\
\text {-Semi-dynamic Datum }\end{array}$ & ITRF 2000 at epoch 2000.0 & $\begin{array}{c}\text { Grid transformation and the } \\
\text { 3- and 7- parameter Bursa- } \\
\text { wolf transformation }\end{array}$ \\
\hline Uzbekistan & $\begin{array}{c}\text { Coordinate System of } 1942 \text { (CS- } \\
42) \\
\text {-Static Datum } \\
\end{array}$ & - & $\begin{array}{l}3 \text {-parameters Molodensky } \\
\text { transformation model }\end{array}$ \\
\hline Israel & $\begin{array}{c}\text { Israel Geodetic Datum } 2005 \\
\text { (IGD05/12) } \\
\text {-Static Datum } \\
\end{array}$ & Updated year 2012 & $\begin{array}{l}\text { 7-parameters Bursa-Wolf } \\
\text { transformation model }\end{array}$ \\
\hline Brunei & $\begin{array}{l}\text { Geocentric Datum for Brunei } \\
\text { Darussalam (GDBD2009). } \\
\text {-Semi-dynamic datum } \\
\end{array}$ & ITRF 2005 at epoch 2000.0 & $\begin{array}{l}\text { 7-Parameter Bursa-Wolf } \\
\text { transformation model }\end{array}$ \\
\hline
\end{tabular}

Table 1 Implementation of datum approaches in several countries

In order to implement an accurate, reliable and persistent datum transformation, there are few parameters need to be considered (Kisa et al., 2009):

i. The structure and accuracy of networks for old and new systems

The latest network is obtained through GNSS technique with ITRF implementation managed as dynamic network which provide accurate, undistorted and homogenous accuracies. While, the old networks emitted by terrestrial techniques managed in static structure and less accurate systematic effects.

ii. The size of transformation area affects transformation accuracy and method

There is possibility of obtaining different transformation accuracies using different approaches for a region. Generally, the necessitated accuracy can be achieved through assessing huge and problematic region in a part. Then, persistence can be obtained by combining these parts.

iii. The sum of frequent points applied in transformation and their distribution affects the accuracy.

Thus, the degree of point density needs to be as high as possible.

iv. The mathematic and stochastic model implemented in datum transformation can be selected with regard to the three factors as described.
The significance factors need to be considered in model selection is the possible systematic effects in a network. These effects can be reckoned as crustal movements, edge measures in different scales and so on. Thus, the models in literature are reckoned as follow:

a) Geometric Transformation Models (Helmert, Bursa-Wolf, Moledenski-Bedakes etc.)

b) Two-parameter Polynomials

c) Finite Elements

d) Interpolation Methods (LSQ, Least Curvature, Triangulation etc.)

\section{CONCLUSION}

In conclusion, the implementation of approach datum for Malaysia, Australia, New Zealand, Uzbekistan, Israel and Brunei have been summarized and explained clearly. The semidynamic datum approach is currently selected by many countries compared to dynamic datum. No country is selected from dynamic datum approach in this study due to most of country preferred static datum and semi-dynamic datum rather than dynamic datum. In order to accomplish a dynamic datum, a continuously network operating GNSS station is significantly required for datum definition due to the continuous monitoring of datum and closely tied to the ITRF. It is challenging to 
establish dynamic datum which is costly and high timeconsuming. However, a country should be able to handle at least 7-parameter transformations and implement Bursa-wolf transformation which is reliable for a large region and small region compared to Molodensky transformation.

\section{ACKNOWLEDGEMENTS}

Authors would like to acknowledge the Ministry of Education (MOE) Malaysia and Universiti Teknologi Malaysia for funding this research under Research University Grant (VOT number: Q.J130000.2527.19H26).

\section{REFERENCES}

Angermann, D., Drewes, H., Gerstl, M., Kelm, R., Kriigel, M., Meisel, B. and Miinchen, D.-., 2003. ITRF Combination Status and Recommendations for the Future.

Bevin, A.J. and J. Hall, 1995. The review and development of a modern geodetic datum. New

Zealand Survey Quarterly, Issue 1: 14-18.

Blick, G., \& Grant, D., 2015. The Implementation of a SemiDynamic Datum in New Zealand - Ten Years the Implementation of a Semi-Dynamic Datum in New Zealand Ten Years On, (January).

Blick, G., Grant, D., Blick, G.,, Grant, D. , 2010. The Implementation of a Semi-Dynamic Datum in New Zealand Ten Years on the Implementation of a Semi-Dynamic Datum in New Zealand - Ten Years On, (April 2010), 11-16.

Ching, K., Chen, K. , 2016. Tectonic effect for establishing a semi- dynamic datum in Southwest Taiwan. Earth, Planets and Space, (January), 0-14. http://doi.org/10.1186/s40623-0150374-0

Dawod, G., Resrach, W., 2014. OPTIMUM GEODETIC DATUM TRANSFORMATION TECHNIQUES FOR GPS OPTIMUM GEODETIC DATUM TRANSFORMATION TECHNIQUES FOR GPS SURVEYS IN EGYPT, (September 2000)

Department of Survey and Mapping Malaysia (DSMM), 2009.Pekeliling Ketua Pengarah Ukur Dan Pemetaan Bilangan 1 Tahun 2009.Garis Panduan Mengenai Sistem Rujukan Koordinat Di Dalam Penggunaan Global Navigation Satellite System (Gnss) Bagi Tujuan Ukur Dan Pemetaan.

Donnelly, N., Information, L., Zealand, N., Crook, C., Information, L., Zealand, N., Stanaway, R. , 2014. Dynamic Datum Transformations in Australia and New Zealand.

Drewes. , 2009. Reference Systems, Reference Frames, and the Geodetic Datum -DREWES.pdf.

Fazilova, D., 2017. Geodesy and Geodynamics The review and development of a modern GNSS network and datum in Uzbekistan. Geodesy and Geodynamics, 8(3), 187-192. http://doi.org/10.1016/j.geog.2017.02.006

Garfunkel, Z., 1981. "Internal structure of the Dead Sea leaky transform (rift) in relation to plate kinematics." Tectonophysics,
80(1), 81-108.

Geoscience Australia (GA) Website. Retrieved April 25, 2019, from https://www.ga.gov.au/scientific-topics/positioningnavigation/geodesy/datums-projections/gda2020

Gill, J., Shariff, N.S., Omar, K.M., Din, A.H.M., Amin, Z.M., 2016. A review on legal traceability of gnss measurements in the Malaysian cadastral practice. International Archives of the Photogrammetry, Remote Sensing and Spatial Information Sciences - ISPRS Archives 42(4W1), pp. 191-197.

Gill, J., Shariff, N.S., Omar, K.M., Din, A.H.M., Amin, Z.M., 2016. Development of a time-dependent 3-parameter helmert datum transformation model: A case study for Malaysia. International Archives of the Photogrammetry, Remote Sensing and Spatial Information Sciences - ISPRS Archives 42(4W1), pp. 181-189.

Grant, D. B., and Pearse, M., 1995. Proposal for a dynamic national geodetic datum for New Zealand. IUGG XXI General Assembly, Colorado, USA. July 2-14

Intergovernmental Committee on Surveying and Mapping (ICSM), 2018, Geocentric Datum of Australia 2020 Technical Manual, Version 1.2

Jakeli. , 2006. Geometric reference system in geodesy.

Land Information New Zealand (LINZ) Website. Retrieved April 25, 2019, from https://www.linz.govt.nz/data/geodeticsystem/datums-projections-and-heights/geodetic-datums/newzealand-geodetic-datum-2000-nzgd2000/nzgd2000-frequently

K, A., Erkek, B., Ekin, L., IV, C., IV, W. G., Datum, K. E. Y. W. ... Registry, L., 2009. DATUM TRANSFORMATION OF SPATIAL DATA AND APPLICATION IN CADASTRE.

Moore, T., Smith, M. 1998. Geodetic transformation, Survey Review, No 270, pp. 509-516.

Mostafa Rabah, Mahmoud Elmewafey, M. H. F., 2016. Datum maintenance of the main Egyptian geodetic control networks by utilizing Precise Point Positioning "PPP" technique.

NGS, 1986: Geodetic Glossary. National Geodetic Survey, National Oceanic and Atmospheric Administration (NOAA), Rockville, MD.

Ramachandran, D., Din, A.H.M., Ibrahim, S.A., Omar, A.H. (2019). Real-time precise point positioning (RT-PPP) for positioning and mapping. Lecture Notes in Civil Engineering Volume 9, 2019, Pages 891-913.

Reit, B., 1998, The 7-parameter transformation to a horizontal geodetic datum, Survey Review, V.34, No. 268, pp. 400-404.

Ronen, H., \& Even-tzur, G., 2017. Kinematic Datum Based on the ITRF as a Precise, Accurate, and Lasting TRF for Israel, 143(4), 1-8. http://doi.org/10.1061/(ASCE)SU.19435428.0000228 .

Shariff, N. S., Musa, T. A., Omar, K., 2014. The Geocentric Datum of Malaysia : Preliminary Assessment and Implications, 71-83. http://doi.org/10.1007/978-3-319-03644-1

Shariff, N. S., Gill, J., Amin, Z. M., Omar, K. M., 2017. TOWARDS THE IMPLEMENTATION OF SEMI-DYNAMIC 
DATUM FOR MALAYSIA, XLII (October), 185-199.

Soler, T., and Marshall, J., 2002. "Rigorous transformation of variancecovariance matrices of GPS derived coordinates and velocities." GPS Solutions, 6(1-2), 76-90.

Walcott, R.I., 1984. The major structural elements of New Zealand, An introduction to the recent crustal movements of New Zealand, Misc. Series 7, Royal Society of New Zealand.

Wdowinski, S., et al., 2004. "GPS measurements of current crustal movements along the Dead Sea Fault." J. Geophys. Res. B: Solid Earth, 109(B5), B05403.

Winefield, R., Crook, C., and Beavan, J., 2010. The application of a localised deformation model after an earthquake. Proceedings of FIG Congress 2010, Sydney, Australia, April $11-16$.

Zulkifli, N.A., Din, A.H.M., Omar and A.H., 2019. The impact of different international terrestrial reference frames (ITRFS) on positioning and mapping in Malaysia. Lecture Notes in Civil Engineering Volume 9, 2019, Pages 671-690.

Revised August 2019 